\title{
Series Active Variable Geometry Suspension for Road Vehicles
}

\author{
Carlos Arana, Member, IEEE, Simos A. Evangelou, Member, IEEE/ASME and Daniele Dini, Member, ASME
}

\begin{abstract}
A new family of electro-mechanical active suspensions that offers significant advantages with respect to passive and semi-active suspensions, while at the same time avoiding the main disadvantages of alternative active solutions, is presented in this paper. The Series Active Variable Geometry Suspension takes a conventional independent passive or semi-active suspension as its starting point, and improves its behavior by actively controlling the suspension geometry with an electro-mechanical actuator. The advantages of this type of suspension are discussed and its simplest variant is studied in detail. Insight on the design process, as well as on the actuator modeling and selection is provided. Moreover, a control system for pitch attitude control of the chassis is presented. Simulation results obtained with a high-fidelity, fullvehicle, non-linear model of a high performance sports car that includes actuator dynamics and saturation limits are shown to confirm the potential of the proposed system.
\end{abstract}

Index Terms-Active suspension, automotive, mechatronics, variable geometry, chassis attitude control.

\section{INTRODUCTION}

Up to this day passive suspensions continue to dominate the market due to 1) their low cost, 2) reliability, 3) small volume requirements, and 4) simplicity [1]. Semi-active suspensions have become very popular in high-end vehicles because they can provide a similar performance to active suspensions regarding chassis isolation from road irregularities [2], at a lower cost and without the necessity of adding bulky equipment. Active suspensions are hitting the market place again, despite some important unresolved issues such as their high cost and power requirements [3], driven by the higher degrees of electrification in modern vehicles and the increased demands from regulators and customers.

Since the late 1990's, active and especially semi-active suspensions have received much attention from manufacturers and popular magazines despite some contradicting initial reviews of their performance [4], [5]. Most types of road vehicles, from high-deck buses, to luxury passenger cars have received new active or semi-active suspensions in the last decade. The application of these technologies to high performance motorbikes has recently become a reality [6], and they are now reaching cars in the $\mathrm{C}$-segment, as $\sim 20 \%$ of roadster drivers were prepared to pay 1700 euros for a semi-active suspension in 2007 [7].

Carlos Arana (carlos.arana-remirez10@imperial.ac.uk) and Simos A. Evangelou (s.evangelou@imperial.ac.uk) are with the Departments of Electrical and Electronic, and Mechanical Engineering at Imperial College London. Daniele Dini (d.dini@imperial.ac.uk) is with the Department of Mechanical Engineering at Imperial College London.

This work was supported by the UK Engineering and Physical Sciences Research Council and by Imperial Innovations.

Manuscript received March 31, 2013.
The Series Active Variable Geometry Suspension (SAVGS) presented in this paper [8], [9], which is a new implementation of the variable geometry active suspension concept [10], [11], aspires to fill the gap between current semi-active and active solutions, offering superior performance than the former while avoiding the main disadvantages of the latter. When compared to other variable geometry alternatives, such as the Delft Active Suspension (DAS) [12] and subsequent developments [13], [14], the SAVGS offers advantages such as an inherent fail-safe behavior and negligible unsprung mass increment. References [15]-[17] are involved with active geometry solutions but deal only with control issues, making no reference to the implementation of the system in a vehicle, nor to the actuator requirements.

The main contributions of this paper, which is part of a research programme that encompasses studying, developing and testing the SAVGS concept and its control strategies, are: 1) to propose a new implementation of the active variable geometry suspension concept, 2) to provide detailed modeling information of both the vehicle and the actuator, 3) to reflect on the key design aspects and to illustrate the design process through the selection of off-the-shelf components for a specific application, 4) to define a suitable control strategy for pitch attitude motion that respects all actuator limitations, and 5) to provide a set of simulation results that demonstrates the potential of the previously dimensioned system.

The outline of the paper is as follows: In Section II the proposed suspension solution is described, and its main advantages highlighted. Section III covers the modeling and dimensioning of the simplest SAVGS variant, while Section IV deals with its control system in the context of pitching motions. Section V presents simulation results obtained with a full-vehicle non-linear model. Finally, Section VI summarizes the main conclusions from this work and outlines the next steps needed for the development of the SAVGS.

\section{SAVGS CONCEPT}

\section{A. Aim}

The SAVGS has been developed with two main objectives: 1) to fulfill the suspension functions better than passive/semiactive solutions (e.g. improved comfort and attitude control), and 2) to avoid or reduce the inherent disadvantages of conventional active suspensions (such as weight and energy consumption). Moreover, it aspires to add new functionalities to passive and semi-active suspension systems. These may include load leveling, active aerodynamics, ride height adjustment, and others. 


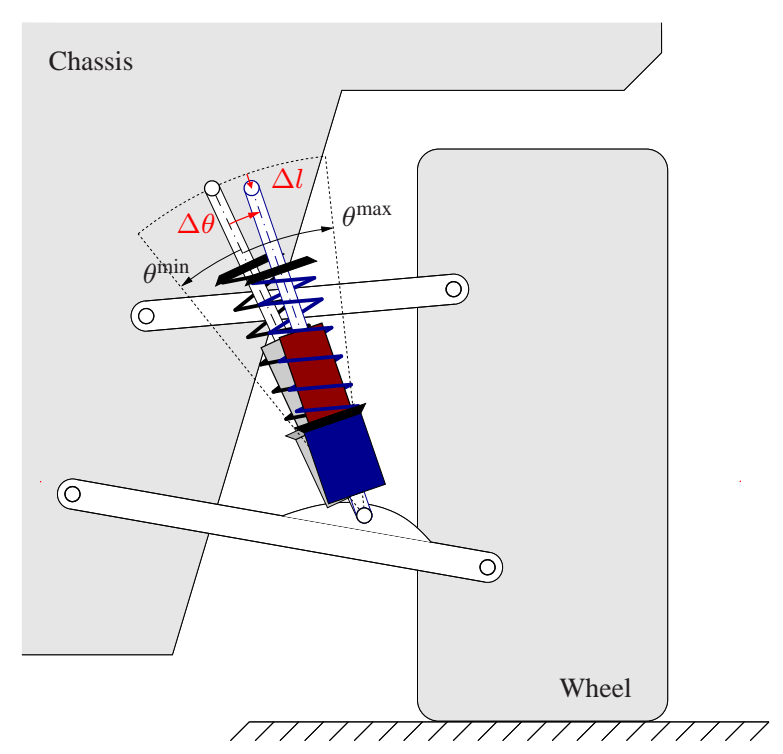

Fig. 1. SAVGS application to a double wishbone suspension. The actuator and mechanism that control the position of the upper end eye of the strut are fixed to the chassis to avoid adding mass to the unsprung side of the suspension.

\section{B. Operating principle and structure}

The SAVGS maintains all elements of a passive or semiactive suspension, and introduces a device between one of the end eyes of the spring-damper unit and its adjacent body. This device, which acts in series with the spring-damper and comprises an electro-mechanical actuator and a mechanism, is able to control the position of the end eye, thus modifying the orientation and elongation of the strut.

Its general application to a car with double wishbone suspension is shown in Fig. 1, although the concept may also be applied to other vehicles and suspension topologies (see [18] for instance). The SAVGS can be implemented in the front, the rear, or both axles of a road vehicle. Ideally the actuator operates between the chassis and the upper end of either the spring, the damper or the spring-damper unit, thus avoiding an increase in unsprung mass. In its simplest embodiment, the mechanism is reduced to a linkage with one or two links. These are shown in Fig. 2 and Fig. 3 respectively.

\section{Comparison with other suspension technologies}

1) SAVGS advantages with respect to passive suspensions: The possibility of actively and independently controlling the force in each quarter of the vehicle leads to the possibility of, among others, 1) self-leveling the car, 2) lifting it for parking or other low-speed maneuvers, 3 ) improving the aerodynamic behavior through chassis attitude and ride height control, 4) reducing the roll angle during turning maneuvers, 5) reducing the pitch angle during acceleration/braking events, 6) adjusting the load transfer distribution between axles (handling), and 7) modifying comfort and road holding characteristics.

2) SAVGS vs. semi-active suspensions: From the list of advantages given in Section II-C1, semi-active solutions cannot tackle (1-3) at all, whilst (4-6) can only be improved during
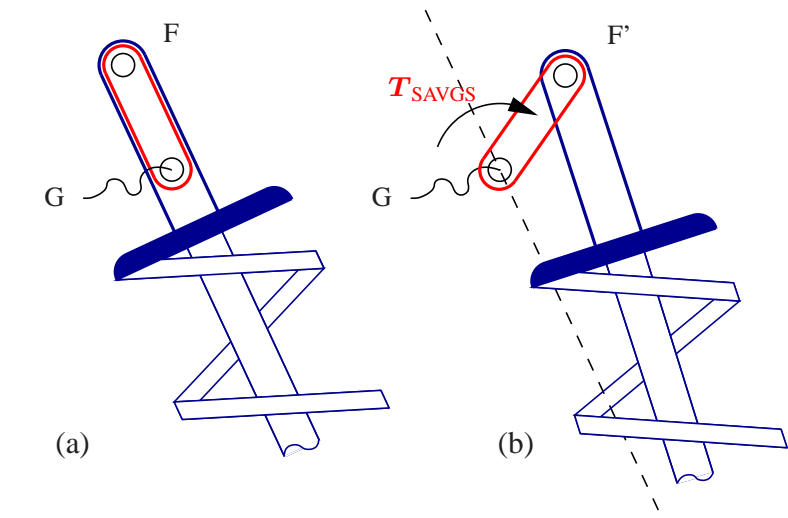

Fig. 2. Single-link variant of the SAVGS. Point $G$ is the joint of the singlelink with the chassis, and point $F$ is the joint of the single-link with the strut end. The spring-damper force as well as the installation ratio [19] are altered due to the rotation of the single-link. The actuation torque, $T_{\mathrm{SAVGS}}$, is applied to the single-link about a longitudinal axis that goes through point $G$.

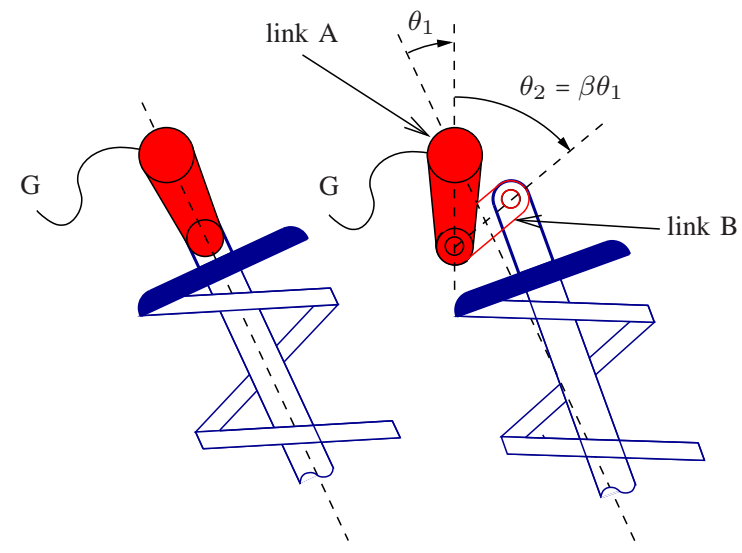

Fig. 3. Duo-link variant of the SAVGS. Link $A$ is connected to the chassis at point $G$. The installation ratio varies less than in the single-link case thanks to a more linear trajectory of the end eye. The rotation of link $B$ is constrained to the rotation of link $A$ via a set of gears (not shown).

transients. However, they are good at improving comfort and road holding with low power consumption. In the case of the SAVGS, comfort and road holding are more demanding in terms of control bandwidth, and further analyses are required to identify the full SAVGS potential.

As both technologies are complementary, a combination of the SAVGS with a semi-active damper (electro-rheological, magneto-rheological or mechatronic) could lead to a very capable and efficient solution.

3) SAVGS vs. alternative active suspensions: The key advantages with respect to other active solutions are:

- Negligible increment of unsprung mass: all components are directly attached to the chassis, or located between the chassis and the spring-damper unit.

- Fail-safe system: if there is a power loss and the SAVGS cannot provide any torque, or if there is a failure that leads to a blockage in the linkage motion, the suspension reverts safely to passive only mode and performs almost exactly as the original passive suspension. For example, if there is a power loss when the system is in the configuration shown in Fig. 2-b, it will revert to Fig. 2-a due to the 
equilibrium of forces acting on the single-link.

- Low actuation force, power and energy requirements: efficient actuators are used, and the system benefits from the change in installation ratio during operation. Furthermore, the control unit may adjust the maximum power consumption, or even switch off the SAVGS if deemed appropriate in order to save energy.

- Use of readily available technology: conventional electric motors, gearboxes, bearings and mechanical links can be used. As there is no need to develop any new technology, the reliability and time-to-market can be greatly improved with respect to more complex active suspensions.

- In line with current trends in the automotive industry of higher levels of hybridization and electrification.

\section{MODELING AND DIMENSIONING}

An overview of the vehicle and actuator models is provided in this section. A few remarks are also made on the dimensioning approach of the single-link variant of the SAVGS for pitch angle control applications.

\section{A. Vehicle model}

Most of the active and semi-active suspension studies are still limited to the well-known quarter-car model [20], and therefore neglect the effect of suspension geometry on the dynamic response of the system [21]. In this work, however, it is important to consider suspension geometry in order to capture the influence of the SAVGS on the installation ratio. Moreover, a full vehicle model has been developed in order to provide a generic and reliable virtual environment in which to test and dimension the SAVGS, and to enable potential dynamic coupling issues between the individual wheel suspensions to be identified.

AutoSim [22] is the symbolic multi-body software chosen as the modeling platform, mainly because of the freedom and flexibility it offers due to the fundamental level at which bodies, forces, state variables etc. are defined.

Fig. 4 shows the general tree structure of the model used. The systems and bodies included are: the chassis $S$; the powertrain (which includes the propeller shaft ICE, crown wheel $C R W$, and differential gear $D F G$ ); the steering system (pinion $P I N$ ); and the suspension system (lower $L W$ and upper $U W$ wishbones, hub carriers $H C$ and $A H C$, and wheels $W H$ ). The parent-child relationships are represented by solid lines accompanied by a letter that indicates the rotational DOF of the child with respect to its parent. Kinematic constraints are indicated with black dashed arrows, forces with solid thick black arrows, and control signals (steering, throttle, brake) with dashed red arrows. Suspension and vertical tire springdamper forces, and anti-roll, steering column, and viscous differential spring-damper moments are shown. Gravitational and aerodynamic forces are not included in the diagram.

The tire model is based on Pacejka's Magic Formula, and aerodynamic drag and downforce are proportional to the square of the forward velocity. The reader is referred to [9] for more information on the vehicle model.

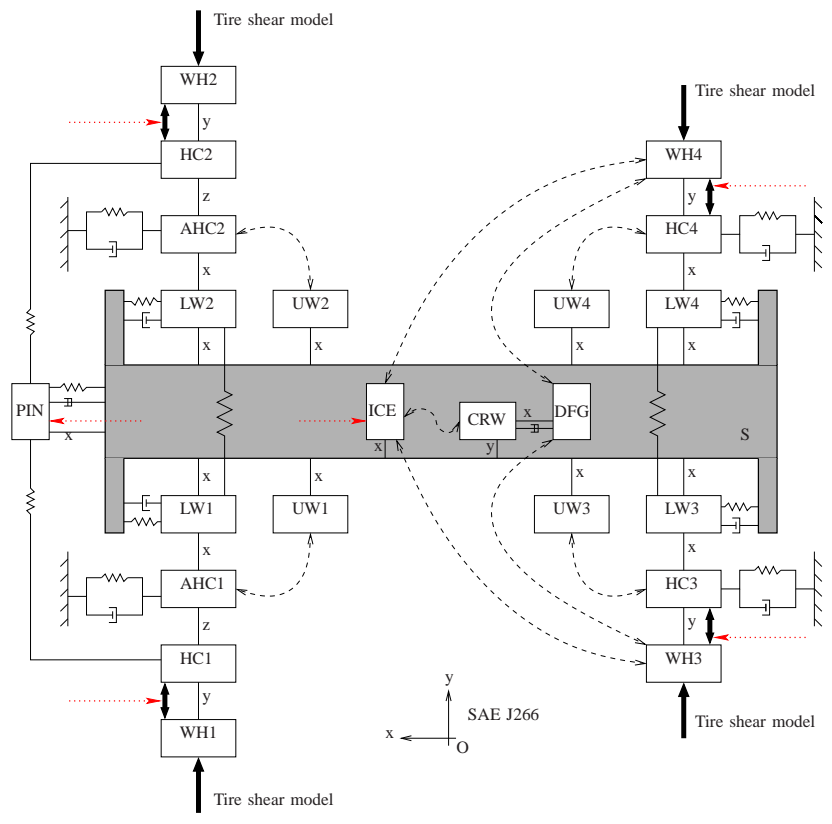

Fig. 4. Tree structure of the vehicle model. The chassis $S$ has six degrees of freedom with respect to the inertial reference frame. All other bodies are defined with rotational degrees of freedom (DOF) only.

\section{B. SAVGS modeling}

Actuator models were not commonly included in active suspension design and control studies until the mid-90's [23]. Nowadays, it is still common practice to neglect or simplify actuator dynamics and limitations during the controller synthesis stages (e.g. [24]). Also, when actuator saturations are included, they are generally modeled as fixed-value limits on the actuation force, independent of the actual operating conditions [25]. In this paper, the focus is on assessing the capabilities of the SAVGS, on quantifying its power and energy requirements, and on identifying potential control issues. Therefore the main actuator dynamics, power losses, and limitations are modeled and included in the synthesis stage.

The main components of the single-link variant of the SAVGS are: the actuator (electric motor + gearbox), and the single-link. The gearbox is needed because electric motors in the desired range of power values, approximately 0.5 to $1.5 \mathrm{~kW}$, offer a torque-speed compromise that is too skewed towards high speed applications.

1) Motor modeling: A permanent magnet synchronous motor (PMSM) has been the actuator of choice due to its high power density, and its excellent performance in servo applications [26]. Motor dynamics are conveniently implemented using the rotor-fixed $d q 0$ reference frame. Considering a surface mounted PMSM, i.e. with no saliency and therefore $L_{d}=L_{q}$, the dynamics are given by [27]:

$$
\begin{aligned}
& \frac{d i_{d}}{d t}=\frac{1}{L_{s}}\left(v_{d}-R_{s} i_{d}+\omega_{e} \lambda_{q}\right), \\
& \frac{d i_{q}}{d t}=\frac{1}{L_{s}}\left(v_{q}-R_{s} i_{q}-\omega_{e} \lambda_{d}\right),
\end{aligned}
$$

where $R_{s}=\frac{R_{\text {line-line }}}{2}$ and $L_{s}=\frac{L_{\text {line-line }}}{2}$ are the $d-q$ phase resistances and inductances, $\omega_{e}=n_{p p} \omega_{r}$ is the electrical 
frequency, with $n_{p p}$ being the number of pole pairs and $\omega_{r}$ the angular speed of the PMSM rotor, $\lambda_{d}=L_{s} i_{d}+\lambda_{a f}$ and $\lambda_{q}=L_{s} i_{q}$ are the stator flux linkages, and $\lambda_{a f}$ is the flux linkage due to the rotor magnets.

In order to include core losses (due to hysteresis and eddy currents), which are significant ( $20 \%$ ) at speeds close to, and above, the rated speed [28], an iron loss resistance, $R_{i}$, is added in parallel with the armature inductance in the $d-q$ equivalent circuits [29]. Thus, $d-q$ currents are split into two components: a magnetizing component, $i_{d_{m}}$ and $i_{q_{m}}$, and an undesirable component that goes through the iron loss resistance. The dynamic equations become:

$$
\begin{aligned}
\frac{d i_{d_{m}}}{d t} & =\frac{1}{\Gamma L_{s}}\left(v_{d}-R_{s} i_{d_{m}}+\Gamma \omega_{e} \lambda_{q_{m}}\right), \\
\frac{d i_{q_{m}}}{d t} & =\frac{1}{\Gamma L_{s}}\left(v_{q}-R_{s} i_{q_{m}}-\Gamma \omega_{e} \lambda_{d_{m}}\right),
\end{aligned}
$$

where $\Gamma=1+\frac{R_{s}}{R_{i}} \approx 1, \lambda_{d_{m}}=L_{s} i_{d_{m}}+K_{e}$ and $\lambda_{q_{m}}=L_{s} i_{q_{m}}$ are the stator flux linkages, and $K_{e}$ is the back EMF constant. The $d-q$ currents are related to their magnetizing components through:

$$
\begin{aligned}
& i_{d}=i_{d_{m}}+\frac{1}{R_{i}}\left(\frac{d \lambda_{d m}}{d t}-\omega_{e} \lambda_{q m}\right), \\
& i_{q}=i_{q_{m}}+\frac{1}{R_{i}}\left(\omega_{e} \lambda_{d m}+\frac{d \lambda_{q m}}{d t}\right) .
\end{aligned}
$$

Applying an amplitude invariant transformation from the frame of the three-phase $a b c$ wye-connected stator of the PMSM to the $d q 0$ frame fixed to the rotor, and considering balanced and sinusoidal back emf, the relationships between voltage, current, and electrical power from/to the bridge converter, expressed in both systems, are given by:

$$
\begin{aligned}
\left|v_{a}\right| & =\left|v_{b}\right|=\left|v_{c}\right|=\sqrt{v_{d}^{2}+v_{q}^{2}}, \\
\left|i_{a}\right| & =\left|i_{b}\right|=\left|i_{c}\right|=\sqrt{i_{d}^{2}+i_{q}^{2}}, \\
P_{\text {bridge }} & =v_{a} i_{a}+v_{b} i_{b}+v_{c} i_{c}=\frac{3}{2}\left(v_{d} i_{d}+v_{q} i_{q}\right) .
\end{aligned}
$$

As the switching frequency of the converter is well above the relevant system dynamics, the desired voltages, $v_{d}^{*}$ and $v_{q}^{*}$, are assumed to be perfectly tracked. Thus, $v_{d}=v_{d}^{*}$, and $v_{q}=v_{q}^{*}$.

The equations for electromagnetic and output torques, $T_{e m}$ and $T_{\text {out }}$, account for mechanical, $T_{m}$, and stray losses:

$$
\begin{aligned}
T_{e m} & =\frac{3}{2} n_{p p} K_{t} i_{q_{m}}, \\
T_{\text {out }}=T_{\text {em }}+T_{m} & =T_{e m}-\frac{\omega_{r}}{\left|\omega_{r}\right|}\left(T_{f}+c_{w}\left|\omega_{r}\right|\right),
\end{aligned}
$$

where $T_{f}$ is the frictional torque, $c_{w}$ the viscous damping coefficient (windage), $K_{t}=\lambda_{a f}-K_{s}$ the torque constant, and $K_{s}$ a degrading coefficient to account for the stray load loss [30]. The introduction of this degrading stray load loss factor also affects the definition of the back EMF constant, $K_{e}$, which becomes $\lambda_{a f}$ when in driving mode, and $\lambda_{a f}-K_{s}$ when in regeneration mode. For numerical reasons the term $\frac{\omega_{r}}{\left|\omega_{r}\right|}$ is substituted with $\frac{\omega_{r}}{\left|\omega_{r}\right|} \cdot \min \left(1, \frac{\left|\omega_{r}\right|}{\omega_{t h}}\right)$, where $\omega_{t h}$ is a small angular velocity.

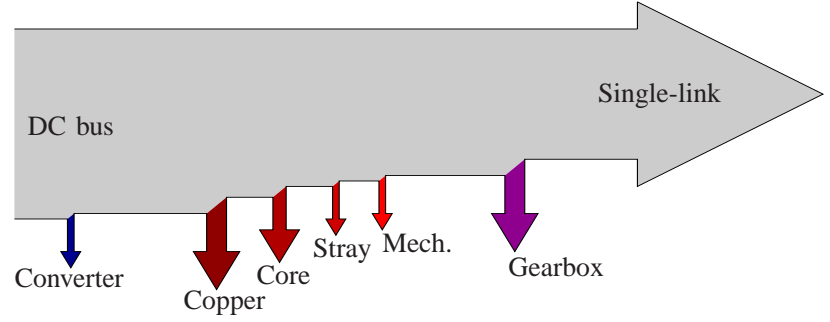

Fig. 5. Power flows from the DC bus to the single-link. Losses in the bi-directional bridge converter, in the PMSM (resistive, core, stray, and mechanical), and in the gearbox are included in the SAVGS model.

2) Gearbox modeling: An epicyclic mechanical gearhead is selected. Magnetic gearboxes, despite promising recent advances on their use for high bandwidth applications [31], are still unable to compete with their conventional counterparts in demanding servo applications.

The angular speed of the high speed shaft (hss) connected to the actuator, is related to that of the low speed shaft $(l s s)$ connected to the single-link, through a fixed gear ratio, $G$ : $\omega_{h s s}=G \omega_{l s s}$. Assuming a constant efficiency for the gearbox, $\eta_{g b x}$, the relationship between the $l s s$ and $h s s$ torques is:

$$
T_{l s s}=\eta_{g b x}^{M} G T_{h s s},
$$

where the mode of operation, $M$, is set to 1 (-1) when the actuator is operating as motor (generator). For numerical reasons, $M$ is made to vary linearly from +1 to -1 for power values below a certain threshold, $P_{t h}$.

$$
M=\frac{\omega_{h s s} T_{h s s}}{\left|\omega_{h s s} T_{h s s}\right|} \cdot \min \left(1, \frac{\left|\omega_{h s s} T_{h s s}\right|}{P_{t h}}\right)
$$

3) Summary of power flows: The power flows and losses included in the SAVGS model are shown in Fig. 5. There is a small voltage drop in the bridge converter due to switching and conducting losses (modeled through $\eta_{\text {bridge }}$ ), but most power dissipation takes place in the PMSM and gearbox. Within the PMSM, losses are very sensitive to the operating conditions, and resistive and core losses dominate. The gearbox is modeled with a constant efficiency, $\eta_{g b x}$.

\section{SAVGS dimensioning}

This section deals with the dimensioning of the singlelink variant of the SAVGS for its use in the control of low frequency dynamics.

1) Kinematic analysis of equilibrium positions: Let's consider the static equilibrium configuration of the passive suspension, as shown in Fig. 6-a. If the suspension is retrofitted with the single-link variant of the SAVGS so that the same static equilibrium configuration is reached (Fig. 6-b), then the unloaded length, $l_{S D_{0}}$, of the spring-damper unit (SD) must be such that it is compressed to $l_{S D}^{s e}=\overline{E G}+l_{S L}$ in the static equilibrium, where $\overline{E G}$ is the distance between points $E$ and $G, l_{S L}$ is the length of the single-link and the superscript se refers to the static equilibrium (i.e. parking configuration).

If the tire load increases due to a load transfer associated with longitudinal or lateral acceleration, or to an increase in sprung mass, the SAVGS can maintain the original passive 

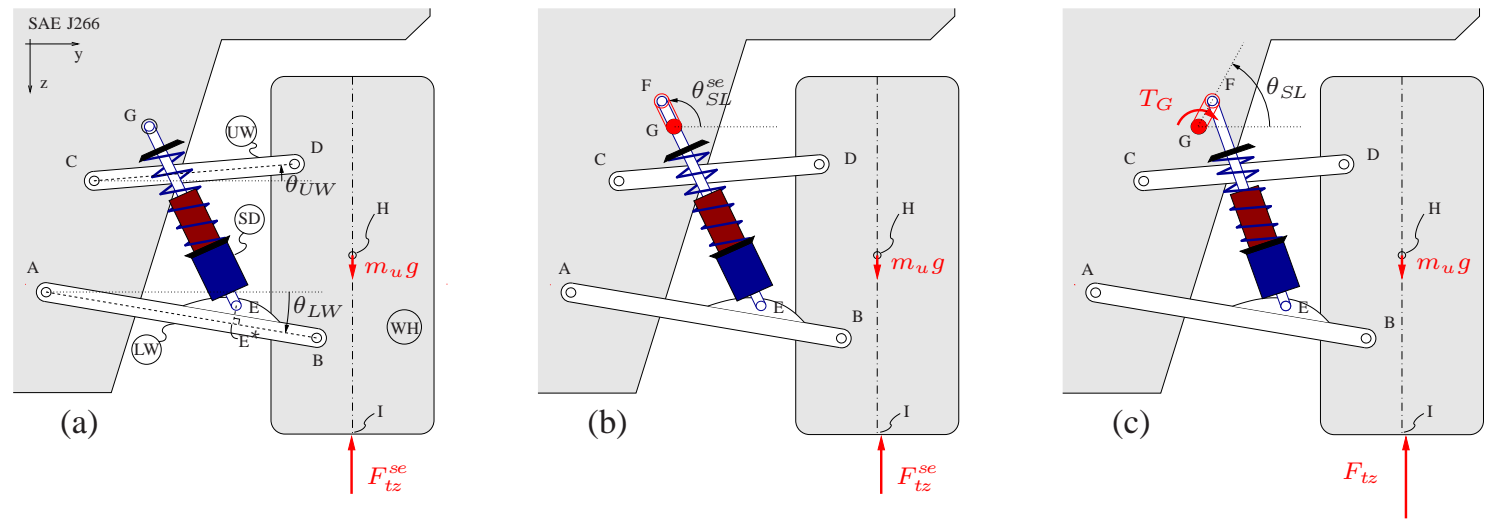

Fig. 6. Static (parking) equilibrium for the passive suspension suspension (a) and for the same suspension retrofitted with the single-link variant of the SAVGS (b). A dynamic equilibrium is shown in (c), where the SAVGS compensates for the increased tire load and ensures that the wishbones remain in their original positions. Angles are measured around the $\mathrm{x}$-axis with respect to the $\mathrm{y}$-axis, and tire forces are negative as drawn. Points A, C and G are fixed to the chassis; points B, D, H and I are fixed to the wheel; points E and F are fixed to the spring-damper unit; and point $\mathrm{E}^{*}$ is fixed to the lower wishbone.

suspension geometry by increasing the force provided by the spring-damper unit. This is achieved by rotating the single-link with respect to its default position, as indicated in Fig. 6-c. In this new dynamic equilibrium position, the torque required from the SAVGS actuator, $T_{G}$, depends on the relative angle between the single-link and the spring damper unit, as well as on the spring-damper force, $F_{S D}=k_{S D} \cdot\left(l_{S D}-l_{S D_{0}}\right)$, where $k_{S D}$ is the spring stiffness. Performing a geometric analysis of Fig. 6-c, an expression can be found for the spring-damper length:

$$
l_{S D}=\overline{E F}=\sqrt{l_{S L}^{2}+a_{1} l_{S L}+a_{o}} .
$$

Coefficients $a_{1}$ and $a_{0}$ are given by:

$$
\begin{aligned}
& a_{0}=\alpha_{0}+\alpha_{1} c_{1}+\alpha_{2} s_{1}, \\
& a_{1}=\alpha_{3} c_{2}+\alpha_{4} s_{2}+\alpha_{5} c_{12}+\alpha_{6} s_{12},
\end{aligned}
$$

where $c_{1}=\cos \left(\theta_{L W}\right), s_{1}=\sin \left(\theta_{L W}\right), c_{2}=\cos \left(\theta_{S L}\right)$, $s_{2}=\sin \left(\theta_{S L}\right), c_{12}=\cos \left(\theta_{L W}-\theta_{S L}\right), s_{12}=\sin \left(\theta_{L W}-\theta_{S L}\right)$, and constants $\alpha_{0}$ to $\alpha_{6}$, which depend only on the passive suspension geometry, are given in (10). Subscripts $y$ and $z$ indicate projections in the $y$ and $z$ directions respectively.

$$
\begin{aligned}
& \alpha_{0}=\overline{A G}^{2}+{\overline{A E^{*}}}^{2}+{\overline{E E^{*}}}^{2}, \\
& \alpha_{1}=2\left(\overline{A G}_{y} \cdot \overline{A E^{*}}-\overline{A G}_{z} \cdot \overline{E E^{*}}\right), \\
& \alpha_{2}=2\left(\overline{A G}_{y} \cdot \overline{E E^{*}}+\overline{A G_{z}} \cdot \overline{A E^{*}}\right), \\
& \alpha_{3}=-2 \overline{A G}_{y}, \\
& \alpha_{4}=-2 \overline{A G_{z}}, \\
& \alpha_{5}=-2 \overline{A E^{*}} \\
& \alpha_{6}=-2 \overline{E E^{*}}
\end{aligned}
$$

Assuming the chassis to be fixed in the inertial reference frame (in its static equilibrium position), the virtual work principle is applied to the system comprised of wishbones and wheel. The tire, gravitational and spring-damper forces are the only actions that produce work:

$$
F_{t z} \delta z_{I}+m_{u} g \delta z_{H}=F_{S D} \delta l_{S D},
$$

where $m_{u}$ is the unsprung mass and $g$ is the gravitational acceleration constant. Given that for small camber angles $\delta z_{I} \approx \delta z_{H}$, and defining the tire and spring force increments as $\Delta F_{t z}=F_{t z}-F_{t z}^{s e}$ and $\Delta F_{S D}=F_{S D}-F_{S D}^{s e}$, it follows from (11) that:

$$
\Delta F_{t z} \delta z_{I}=\Delta F_{S D} \delta l_{S D}
$$

Solving for the tire force increment:

$$
\Delta F_{t z}=\Delta F_{S D} \frac{d l_{S D}}{d z_{I}}=\Delta F_{S D} \frac{d l_{S D}}{d \theta_{L W}} \frac{d \theta_{L W}}{d z_{I}},
$$

where $\Delta F_{S D} \frac{d l_{S D}}{d \theta_{L W}}$ depends on the single-link length and angular position, but $\frac{d \theta_{L W}}{d z_{I}}$ depends solely on the passive suspension geometry. Differentiating (8) with respect to $\theta_{L W}$ leads to:

$$
\frac{d l_{S D}}{d \theta_{L W}}=\frac{1}{2 l_{S D}}\left[-\alpha_{1} s_{1}+\alpha_{2} c_{1}-l_{S L}\left(\alpha_{5} s_{12}-\alpha_{6} c_{12}\right)\right],
$$

and the spring-damper force increment is simply:

$$
\Delta F_{S D}=k_{S D}\left(l_{S D}-l_{S D}^{s e}\right) .
$$

The spring-damper unit length in the static equilibrium, $l_{S D}^{s e}$, is obtained from (8) by making $\theta_{S L}=\theta_{S L}^{s e}$, where by simple geometric consideration:

$$
\theta_{S L}^{s e}=\arctan \left(\frac{\overline{A G_{z}}+\overline{A E^{*}} s_{1}-\overline{E E^{*}} c_{1}}{\overline{A G_{y}+\overline{A E^{*}} c_{1}+\overline{E E^{*}} s_{1}}}\right)-\pi .
$$

Finally, to calculate the torque provided by the SAVGS in the new dynamic equilibrium, the principle of virtual work is once again used, this time applied to the single-link:

$$
T_{G} \delta \theta_{S L}=F_{S D} \delta l_{S D}
$$

Solving (11) for the static equilibrium case leads to:

$$
F_{S D}^{s e}=\left.\left(F_{t z}^{s e}+m_{u} g\right)\left(\frac{d z_{I}}{d \theta_{L W}}\right) \frac{d \theta_{L W}}{d l_{S D}}\right|_{s e},
$$

and the spring-damper force, $F_{S D}$, can be computed by adding (15) and (18). Finally, solving (17) for the torque:

$$
T_{G}=F_{S D} \frac{d l_{S D}}{d \theta_{S L}},
$$

where $\frac{d l_{S D}}{d \theta_{S L}}$ is obtained by differentiating (8):

$$
\frac{d l_{S D}}{d \theta_{S L}}=\frac{l_{S L}}{2 l_{S D}}\left(-\alpha_{3} s_{2}+\alpha_{4} c_{2}+\alpha_{5} s_{12}-\alpha_{6} c_{12}\right) .
$$




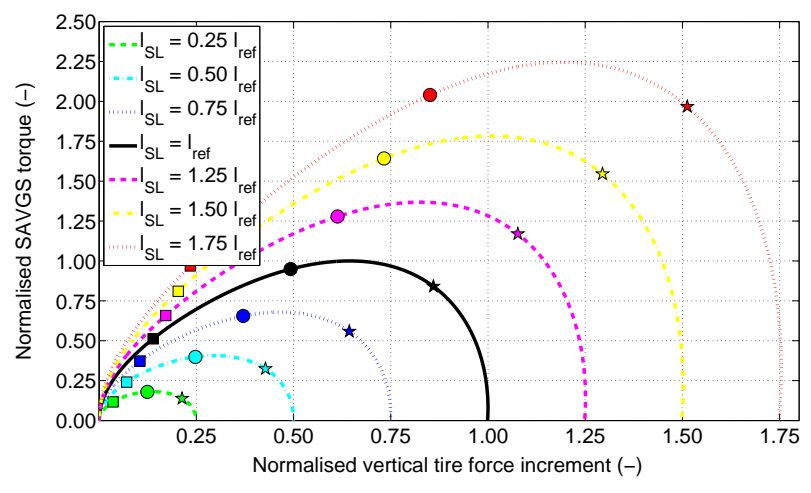

Fig. 7. Normalized SAVGS torque vs. normalized tire force increment for various single-link lengths and 0 to $180^{\circ}$ single-link rotations with respect to the static equilibrium position. Markers correspond to $45^{\circ}$ ( $\left.\square\right), 90^{\circ}$ (०) and $135^{\circ}$ (灾) rotation values.

2) Vehicle properties: To illustrate the component selection, the SAVGS is considered to be retrofitted to a high performance sports car, similar to a Ferrari F430. The main vehicle parameters are given in Table I in the Appendix.

3) Single-link characteristics: The fundamental properties of the single-link are its mass, inertia, and length. Its mass and inertia are small compared to those of the actuator, and therefore are not critical design parameters. On the other hand, its length completely determines 1) the additional suspension force that can be provided by the SAVGS, 2) the torque requirements for the actuator, 3) the achievable increment of ground clearance, and 4) the working space that is needed.

Using (13) and (19), the vertical tire load increment and the associated SAVGS torque can be calculated as a function of the single-link angle for various single-link lengths. Results are shown in Fig. 7, where values have been normalized by those corresponding to a $28 \mathrm{~mm}$ long single-link in order to highlight that shorter links offer a better ratio of maximum achievable tire load increment over SAVGS torque requirements.

Once the desired maximum tire load increment and ground clearance increment have been selected, the minimum singlelink length that can provide this performance can be calculated. Longer links should be avoided, as they would lead to an unnecessary increase in torque demands, components mass, and packaging complexity. Bearing this in mind, single-link lengths of $15 / 11 \mathrm{~mm}$ have been selected for the front/rear axles of the generic sports car under consideration.

4) Actuator selection: The key design parameters are the DC bus voltage, motor power, gear ratio, and maximum torque/speed envelope. The power and voltage of the motor determine the bandwidth of the control that can be performed, whereas the gear ratio modifies the relationship between torque and speed. Moreover, as the actuator torque-speed envelope is the intersection between the motor and gearbox output envelopes, the gear ratio should equalize these in order to avoid oversizing any of the components.

The off-the-shelf motor and gearbox selected are shown in Fig. 8 and the full set of parameter values is given in Table II in the Appendix. The continuous and peak output torque-speed envelopes for both the motor and gearbox are depicted in Fig. 9 along with the overall efficiency contours for the actuator.

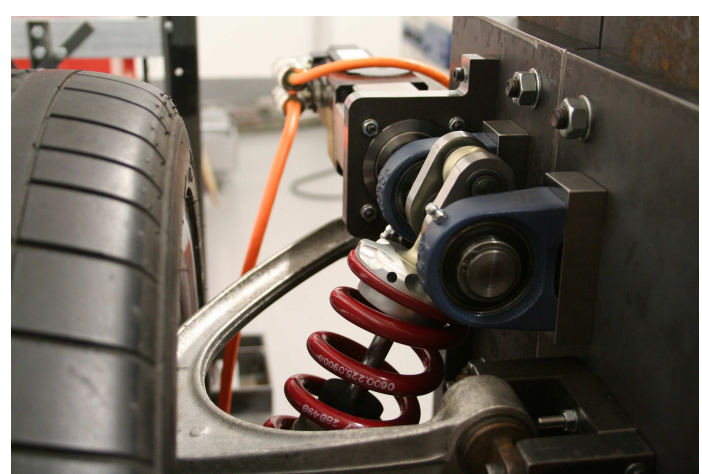

Fig. 8. Selected actuator installed in the SAVGS test facility being developed at Imperial College London.

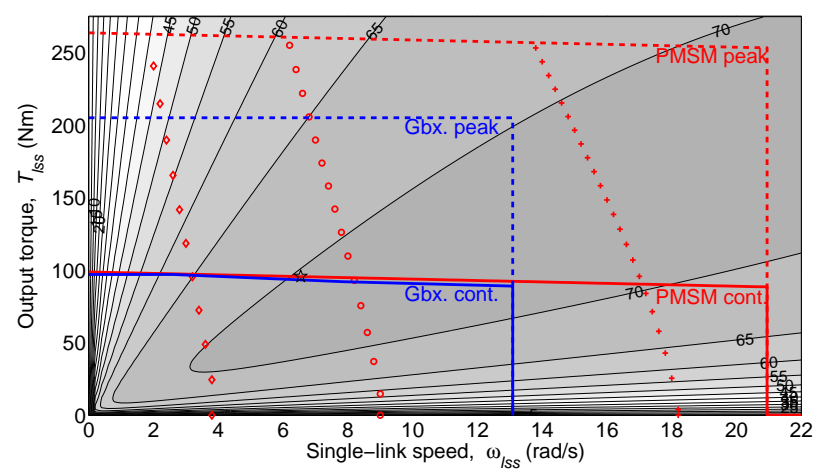

Fig. 9. Actuator steady state characteristics. Peak (dashed) and continuous (solid) output torque vs. output speed envelopes, as limited by the PMSM (red), and the gearbox (blue).

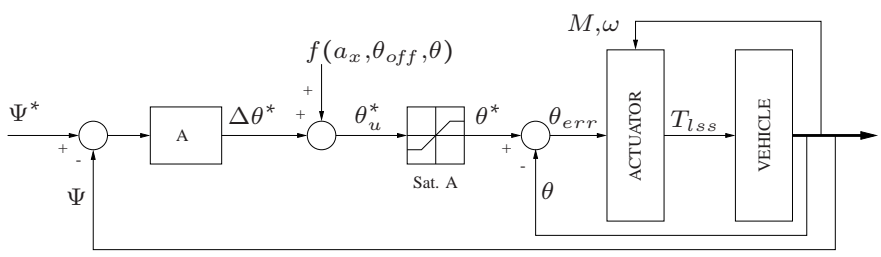

Fig. 10. Outer loop in the pitch control scheme for one of the actuators.

Also, maximum achievable steady state speeds are shown as a function of the DC voltage: $70 \mathrm{~V}(\diamond), 160 \mathrm{~V}(\circ)$, and $320 \mathrm{~V}$ (+). Rated output torque and speed for the PMSM @ 160V DC is indicated by $\begin{gathered}\text { s. } \\ \text {. }\end{gathered}$

\section{CONTROL SCHEME FOR PITCHING EVENTS}

In order to illustrate the performance of the SAVGS in low bandwidth applications, a scheme for pitch angle control during acceleration and braking maneuvers is presented in this section. Corresponding results are shown in Section V.

The overall control strategy, depicted in Fig. 10, is as follows: first, a suitable position reference, $\theta^{*}$, is generated for each of the four actuators in the vehicle; then each individual reference is tracked by various inner loops (see Fig. 11).

The reference rotation angle for the single-link, $\theta^{*}$, is calculated as the addition of two terms: $f$, which is either the desired offset angle (for low longitudinal accelerations), or the actual angular position of the single-link (for mid to 
high longitudinal accelerations), and $\Delta \theta^{*}$, which is the output of a controller (block $A$ ) that aims to track a certain pitch angle reference. This is explained in more detail in Section IV-A.

The internal scheme for each actuator, shown in Fig.11 and explained in Section IV-B, IV-C and IV-D, is designed and tuned starting from the innermost PI controllers, $C 1$ and $C 2$, and finishing with the outermost PID block, $B$. In an initial stage, gains are selected by applying standard Matlab/Simulink design tools to a quarter-car representation of the car. Final validation and fine tuning of the full-vehicle control strategy is performed with AutoSim. In this scheme, feedback loops and saturations are needed to ensure that the actuator operates effectively within its physical and design boundaries (voltage, power, current, torque, and speed constraints). Standard antiwindup schemes based on conditional integration [32] are built in controllers $C 1, C 2$, and $B$.

\section{A. Position control of the single-link}

Position control of the single-links has been preferred over the torque control presented in [9], because 1) it allows to reach larger rotation angles (close to $180^{\circ}$ from the equilibrium position) without compromising stability, and 2) it allows to operate the single-links from an offset position, thus improving the controllability of the system.

The reference angular position for the single-link is kept between its equilibrium position and a maximum angle which should be less than or equal to $180^{\circ}$. It is calculated as the addition of the two terms given in (21):

$$
\begin{array}{r}
f=\frac{\theta+\theta_{o f f}}{2}+\frac{\theta-\theta_{\text {off }}}{\pi} \cdot \arctan \left[a_{x_{t h 1}}\left(a_{x}-a_{x_{t h 2}}\right)\right], \\
\Delta \theta^{*}=K_{p}\left(\Psi^{*}-\Psi\right)+K_{d} \frac{d\left(\Psi^{*}-\Psi\right)}{d t},
\end{array}
$$

where $a_{x}$ is the longitudinal acceleration of the vehicle, $\theta$ is the actual single-link angle, $\theta_{\text {off }}$ is the desired offset angle, $a_{x_{t h 1}}$ and $a_{x_{t h 2}}$ are tunable constants, and $\Psi$ and $\Psi^{*}$ are the actual and reference pitch angles for the chassis. The control gains, $K_{p}$ and $K_{d}$, are selected from within a sensible parameter space so that they lead to a fast but non-oscillatory response.

The term (21a) varies smoothly from $\theta_{\text {off }}$ for longitudinal accelerations below $a_{x_{t h 2}}$, to the actual single-link angle for larger longitudinal accelerations. At low longitudinal accelerations, an offset angle is desirable in order to 1) increase the gain of the system (the vehicle is insensitive to small singlelink rotations about its equilibrium position), and 2) allow the actuator to push the chassis upwards, as in the case without offset, but also to let it move downwards. Transient response is thus improved, as the actuators in both axles are poised to contribute simultaneously towards a better pitch control.

Once the longitudinal acceleration exceeds a minimum threshold, the term (21a) evolves towards the actual single-link angle. This ensures that, as long as the SAVGS is physically able to generate the required suspension force, the steady state pitch angle error is zero. Moreover, it allows $K_{p}$ and $K_{d}$ gains to be reduced, thus improving the stability of the system.

\section{B. Torque, current and speed limitations}

The reference angular position for the single-link is tracked by a controller that generates a suitable reference for the torque-generating current in the motor, $i_{q_{m}}$ (controller $B$ ). This reference should not change sign frequently if backlash issues in the gearbox are to be avoided. Furthermore, it should not exceed the maximum continuous/peak values allowable for the PMSM and its servo-drive (22a), and it should not lead to motor torques that could damage the gearbox (22b).

$$
\begin{gathered}
\sqrt{i_{d}^{2}+i_{q}^{2}} \leq I^{\max } \\
T_{h s s} \leq \frac{T_{l s s}^{\max }}{\eta_{g b x}^{M} G}
\end{gathered}
$$

In (22), $I^{\max }$ and $T_{l s s}^{\max }$ are set to low values for common events in order to maximize the life of the actuator, and equal to the peak operational limits for exceptional events, such as an emergency braking maneuver. This has been implemented by making $I^{\max }$ and $T_{l s s}^{\max }$ vary from their continuous to their peak limits depending on the longitudinal acceleration of the vehicle (analogous to (21a)).

In addition to these corrections, which are imposed in blocks Sat. B1 and Sat. B2, a feedback loop that modifies the reference current has been implemented in order to prevent the motor from exceeding its maximum allowable speed, or that of the gearbox. Also, a lower speed limit needs to be imposed when the PMSM is operating as a generator, as otherwise the back emf may become too large, and compromise the controllability of the PMSM. This feedback term is given in (23b), where $K_{\omega}=2$ is the feedback gain.

$$
\begin{aligned}
\omega_{h s s}^{\max } & = \begin{cases}\omega_{m}^{\max } & \text { when in motor mode } \\
\omega_{g}^{\max }<\omega_{m}^{\max } & \text { when in generator mode }\end{cases} \\
g(M, \omega) & =\frac{\omega_{h s s}}{\left|\omega_{h s s}\right|} \cdot\left[\max \left(\left|\omega_{h s s}\right|, \omega_{h s s}^{\max }\right)-\omega_{h s s}^{\max }\right] \cdot K_{\omega}
\end{aligned}
$$

\section{Motor control}

Zero-direct axis control, or constant torque angle control [33], has been chosen because it maximizes torque per ampere, and leads to high efficiencies comparable to those obtained with loss minimization control strategies [34].

The control aims are to 1) keep the magnetizing component of the $d$-current equal to zero, and to 2) control $i_{q_{m}}$ so that the desired torque is generated. These objectives are fulfilled by appropriate selection of the phase voltages applied to the PMSM. In the model, the control variables are the modulation indexes, which are defined as the ratio between the fast average of the $d$ (or $q$ ) voltage over the maximum possible phase voltage amplitude: $m_{d}=\frac{\widehat{v_{d}}}{V^{\max }}$, and $m_{q}=\frac{\widehat{v_{q}}}{V^{\max }}$. Moreover, we can assume $m_{d}=m_{d}^{*}=\frac{v_{d}^{*}}{V^{\max }}$ and $m_{q}=m_{q}^{*}=\frac{v_{q}^{*}}{V^{\max }}$, and therefore $v_{d}=V^{\max } m_{d}^{*}$, and $v_{q}=V^{\max } m_{q}^{*}$. It is worth noting that for numerical convergence, it is not desirable to have equal gains in the $d$ and $q$ branches (blocks $C 1$ and $C 2$ ).

\section{Voltage and power limitations}

In order for the bridge converter to remain in its linear range of operation, (24) must be satisfied.

$$
m=\sqrt{m_{d}^{2}+m_{q}^{2}} \leq 1
$$




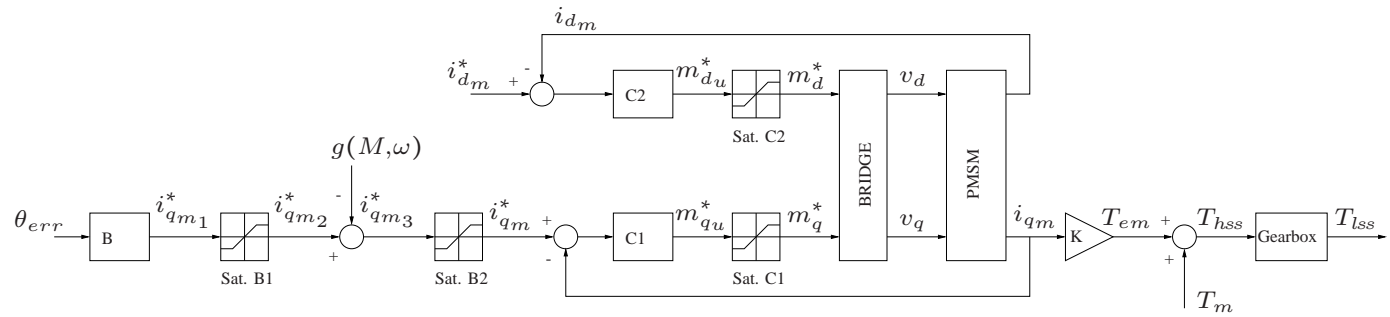

Fig. 11. Control scheme for one of the four SAVGS actuators.

Furthermore, the maximum available phase voltage with space vector modulation is: $V^{\max }=\eta_{\text {bridge }} \frac{V_{D C}}{\sqrt{3}}$ [35]. This value has to be further reduced if power is to be limited. Assuming $\left|i_{d} v_{d}\right| \ll\left|i_{q} v_{q}\right|$, the maximum available voltage becomes:

$$
V^{\max }=\eta_{\text {bridge }} \cdot \min \left(\frac{V_{D C}}{\sqrt{3}}, \frac{2 P^{\max }}{3\left|i_{q}\right|}\right) .
$$

These constraints are imposed in blocks Sat. C1 and Sat. C2.

\section{RESULTS AND DISCUSSION}

Results are presented in this section to illustrate the performance of the SAVGS in low bandwidth control applications. In particular, its ability to maintain a constant chassis attitude, $\left(\Psi^{*}=0\right)$, during acceleration and braking is studied.

A soft power constraint of $500 \mathrm{~W}( \pm 10 \%)$ for each actuator has been imposed through (25), and a DC voltage of $160 \mathrm{~V}$ have been considered in the simulations.

\section{A. Simulated maneuvers}

All results shown correspond to the vehicle driving in a straight line at varying forward speeds and acceleration levels.

1) Maneuver \#1: The first simulated event comprises a hard acceleration phase from 0 to $100 \mathrm{~km} / \mathrm{h}$ in $6.5 \mathrm{~s}$, followed by a $2 \mathrm{~s}$ constant speed period, and an emergency braking in which the deceleration rate averages $1.1 \mathrm{~g}$, as shown in Fig. 12. Results are shown in Fig. 14 to Fig. 16.

2) Maneuver \#2: The second set of simulations deals with a more common event: joining/exiting a highway from/to a low speed lane. The velocity profiles simulated include an acceleration phase from a typical urban environment speed of $50 \mathrm{~km} / \mathrm{h}$, to $120 \mathrm{~km} / \mathrm{h}$, followed by $5 \mathrm{~s}$ at constant velocity and a final exit from the highway, decelerating back to $50 \mathrm{~km} / \mathrm{h}$. The acceleration/deceleration phases have been made to last from $3 \mathrm{~s}$ to $10 \mathrm{~s}$, with constant acceleration/deceleration rates varying from 2 to $6 \mathrm{~m} / \mathrm{s}^{2}$. The SAVGS actuator has been limited at all times to its continuous torque-speed envelope. Results are shown in Fig. 17.

\section{B. Model validation}

It is desirable to validate simulation results experimentally. However, substantial resources are needed to ensure that a test track, a vehicle equipped with a prototyped version of the SAVGS, a driver, and all necessary sensors are available for testing. Such an investment will follow in later stages of development of the SAVGS, and at the moment model validation is performed on a theoretical basis.
As indicated in [36], the first step in the validation process is to ensure that the model built by AutoSim is the same as the one conceived by the analyst. Positions of all points, orientations of all bodies, and initial forces and moments have been checked and confirmed to be as intended.

The second step in the validation process aims to prove that the model built is simulated with sufficient accuracy. A power balance is proposed in [37] and a similar approach is followed here. An energy balance check is performed at the end of each time step in the simulation. The general expression for the energy error, $E_{\text {err }}$, from the beginning of the simulation at $t=0$ up until any given time, $t^{*}$, is:

$$
E_{\text {err }}\left(t^{*}\right)=\int_{0}^{t^{*}} P_{\text {in }} d t-\int_{0}^{t^{*}} P_{\text {out }} d t-\left(E_{\text {sys }}\left(t^{*}\right)-E_{\text {sys }}(0)\right)
$$

The energy input and output terms contain information related to the energy:

- provided by the internal combustion engine,

- provided by the driver through the steering wheel,

- provided by (to) the DC bus to (from) the four bridge converters of the SAVGS,

- dissipated due to aerodynamic forces,

- dissipated due to tire slip forces,

- dissipated due to damping forces in the suspension struts, viscous differential, tires (due to radial damping), and steering column,

- dissipated in the brakes, and

- dissipated in the actuators: in the bridge converters; in the PMSMs (copper, core, stray, and mechanical); and in the gearboxes,

and the change of energy in the system, $\left(E_{\text {sys }}\left(t^{*}\right)-E_{\text {sys }}(0)\right)$, refers to increments in:

- kinetic energy of all bodies,

- gravitational potential energy of all bodies,

- energy stored in all springs: struts, anti-roll bars, tires (radial), steering column, and steering rack, and

- energy stored in electrical inductances.

Thanks to the quality of the code produced by AutoSim and to the small time step used in the simulations to capture actuator dynamics, the energy imbalance is negligible in all cases, as it can be seen in Fig. 13. The energy provided to the vehicle exceeds $700 \mathrm{~kJ}$ whereas the energy imbalance remains less than $3 \mathrm{~J}$. That is, the energy that is not properly accounted for by the model represents $\sim 0.0004 \%$ of the total energy provided to the system. Therefore simulation accuracy is considered to be appropriate. 


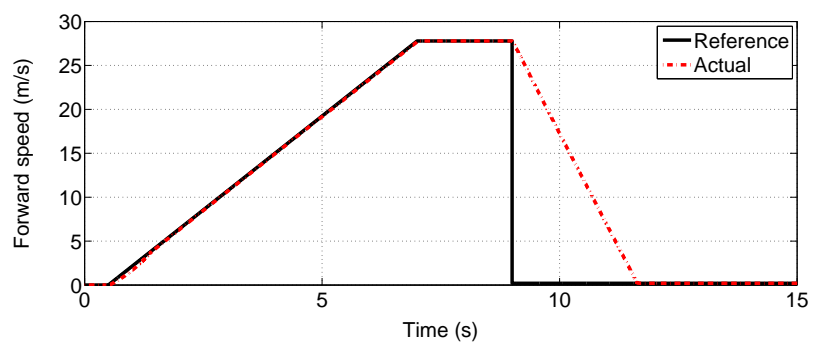

Fig. 12. Forward speed profiles for maneuver \#1.

\section{Results}

1) Maneuver \#1: The pitch time response of the vehicle retrofitted with the SAVGS is compared to that obtained with the original passive suspension in Fig. 14. The SAVGS performs very well both under steady acceleration conditions (zero pitch in the acceleration phase, more than 50\% pitch reduction during the emergency braking maneuver), and in terms of transient response (30-80\% reduction). The introduction of an offset angle $\left(\sim 90^{\circ}\right)$ in the single-link position control leads to significant improvements during transients.

The total electric power and energy consumption for the whole vehicle suspension units are shown in Fig. 15. Values are low for both control strategies (with/without offset): peak power consumption of $1.97 / 1.20 \mathrm{~kW}$, peak power regeneration of $1.4 \mathrm{~kW}$, and average power consumption of $142 / 83 \mathrm{~W}$. For the offset case, the power needed to keep the single-link at that offset position is approximately $40 \mathrm{~W}$ per actuator.

For the same event, the output torque-speed operating points of the actuator (offset case only) are plotted in Fig. 16, alongside the gearbox envelopes for continuous and peak operation. The output torque remains within the continuous envelope at all times, except for a small incursion during the braking phase. This is allowed, as mentioned before, because the longitudinal acceleration exceeds $1 \mathrm{~g}$, and is considered to be an exceptional event by the control system. Note the reduced speed limit ( $\sim 5 \mathrm{rad} / \mathrm{s})$ that the control system imposes when the PMSM is operating as a generator in order to maintain full controllability of the system, and the effect of the power limit on the reachable output points.

2) Maneuver \#2: Maximum/minimum pitch values for each case are shown in Fig. 17. The pitch envelope is significantly narrowed thanks to the use of the SAVGS, particularly with the control system that operates the single-link from an offset position. In particular, peak pitch angles are reduced by $\sim 0.5^{\circ}$ when no offset is included in the control, and by $\sim 0.75^{\circ}$ when an offset of $\sim 90^{\circ}$ is used. Focusing on the $3 \mathrm{~s}$ acceleration and braking events, this means that the front/rear ground clearance variation is reduced from $127 / 79 \mathrm{~mm}$ for the passive case, to $57 / 31 \mathrm{~mm}$ for the SAVGS with offset control.

\section{CONCLUSION}

This paper introduces a new type of series electromechanical active suspension for road vehicles. The SAVGS can be applied to a wide range of vehicles and suspension topologies, and offers significant advantages with respect to passive and semi-active solutions. Moreover, it does not suffer

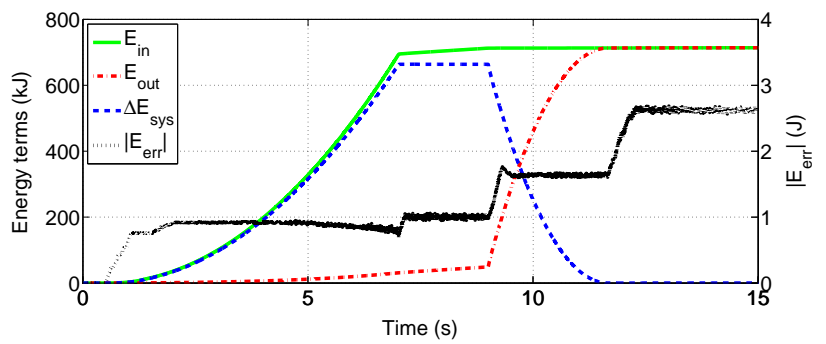

Fig. 13. Input $\left(E_{\text {in }}=\int_{0}^{t} P_{\text {in }} d t\right)$, output $\left(E_{\text {out }}=\int_{0}^{t} P_{\text {out }} d t\right)$ and accumulated $\left(\Delta E_{\text {sys }}=E_{\text {sys }}(t)-E_{\text {sys }}(0)\right)$ energy terms for maneuver \#1. The energy error is equivalent to a constant power error of less than $0.2 \mathrm{~W}$.

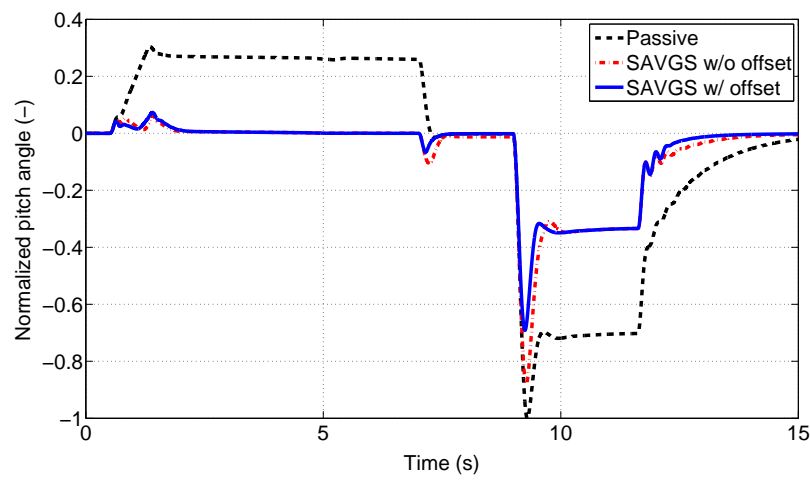

Fig. 14. Pitch angle evolution for maneuver \#1.

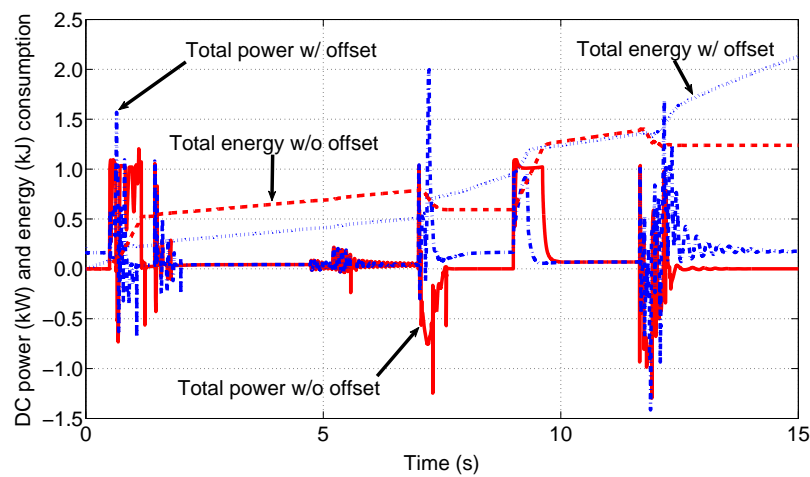

Fig. 15. Total electric power and energy consumption by the SAVGS during manoeuver \#1.

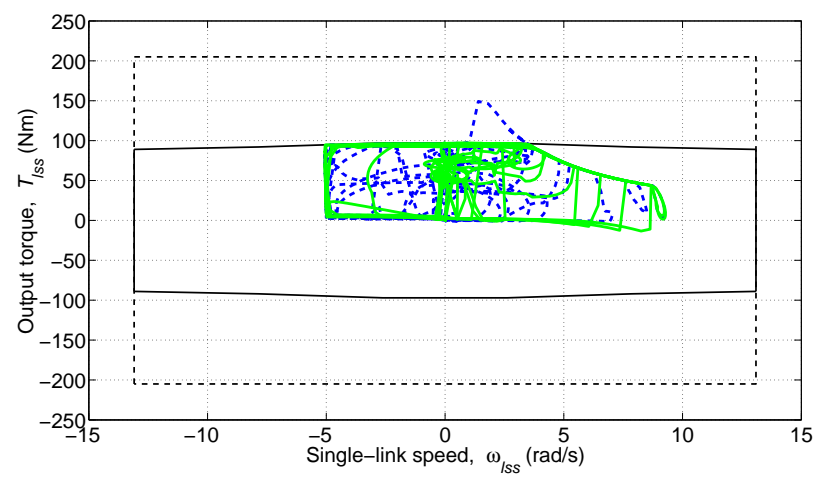

Fig. 16. Output SAVGS torque vs. single-link speed for one front (dashed blue) and one rear (solid green) actuator during maneuver \#1. 


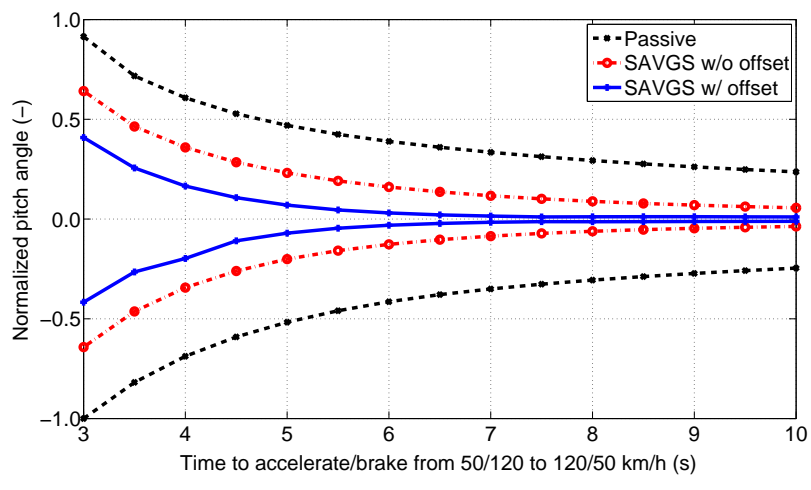

Fig. 17. Peak diving/squatting angles for a series of maneuvers in which the vehicle is simulated to join/exit a highway from/to a low speed lane.

from the main drawbacks of alternative active suspensions, such as high power and energy requirements, increment of unsprung mass, or fail safety issues.

The paper also deals with the assessment of the SAVGS potential for low bandwidth control applications, and the dimensioning process for its simplest (single-link) variant. In contrast with most of the suspension studies in the literature, the full-vehicle multi-body model developed includes the suspension geometries, a pitch angle control system, detailed actuator dynamics, and all the actuator limitations (voltage, power, speed, torque and current constraints) in order to provide realistic results.

Simulations carried out for pitching events demonstrate that the SAVGS is capable of significantly improving the chassis attitude control of a heavy high-performance sports car. In steady state conditions, the selected actuators, which weight approximately $6 \mathrm{~kg}$ each and comprise off-the-shelf components, are able to maintain the chassis leveled except in the most demanding situations. With a maximum power limit of $500 \mathrm{~W}$ per actuator, peak squatting/diving angles during transients are reduced by at least $30 \%$.

Future work includes 1) SAVGS control of suspension functions for various vehicle classes under cornering and running over rough road surfaces, 2) SAVGS and passive components codesign and optimisation, 3) development of advanced control strategies that take into account parameter uncertainties, and 4) experimental testing and validation of simulation models and control strategies.

\section{APPENDIX \\ PARAMETER VALUES}

TABLE I

MAIN VEHICLE PARAMETERS

\begin{tabular}{lcr}
\hline Parameter & Units & Value \\
\hline Total mass/Sprung mass & $\mathrm{kg}$ & $1525 / 1325$ \\
Wheelbase/Height of centre of mass & $\mathrm{mm}$ & $2600 / 424$ \\
Weight distribution (front/rear) & $\%$ & $43 / 57$ \\
Spring stiffness (front/rear) & $\mathrm{N} / \mathrm{mm}$ & $92 / 158$ \\
Tire stiffness (front \& rear) & $\mathrm{N} / \mathrm{mm}$ & 275 \\
Installation ratio (front \& rear) & - & 0.56 \\
\hline
\end{tabular}

TABLE II

SINGLE-LINK, PMSM AND GEARBOX PARAMETERS

\begin{tabular}{lcr}
\hline Parameter & Units & Value \\
\hline Single-link length (front/rear) & $\mathrm{mm}$ & $15 / 11$ \\
\hline$n_{p p}$ & - & 4 \\
$L_{s}$ & $\mathrm{mH}$ & 2.05 \\
$R_{s}$ & $\Omega$ & 0.91 \\
$R_{i}$ & $\Omega$ & 250 \\
$\lambda_{a f}$ & $\mathrm{mV} \mathrm{s} / \mathrm{rad}$ & 61.8 \\
$K_{s}$ & $\mathrm{mV} \mathrm{s} / \mathrm{rad}$ & 4.6 \\
$T_{f}$ & $\mathrm{Nm}$ & 0.026 \\
$c_{w}$ & $\mathrm{Nm} \mathrm{s} / \mathrm{rad}$ & $3.82 \cdot 10^{-5}$ \\
Motor mass & $\mathrm{kg}$ & 2.9 \\
Motor rated power (@ 160/320 V) & $\mathrm{kW}$ & $0.70 / 1.31$ \\
Motor rated speed (@ 160/320 V) & $\mathrm{rpm}$ & $2500 / 5500$ \\
\hline G & - & 40 \\
$\eta_{g b x}$ & - & 0.90 \\
$T_{l s s}^{\text {peak }}$ & $\mathrm{Nm}$ & 205 \\
$T_{l s s}^{\text {cont }}$ for 20000h life & $\mathrm{Nm}$ & $89-97$ \\
Gearbox mass & $\mathrm{kg}$ & 3 \\
\hline
\end{tabular}

TABLE III

$\left[K_{p}, K_{i}, K_{d}\right]$ CONTROL Gains

\begin{tabular}{lr}
\hline Controller & Gains \\
\hline A (front/rear) & {$[70,0,14] /[400,0,80]$} \\
B 1 & {$[200.0,1064.4,8.35]$} \\
C1 & {$[0.5995,276.983,0]$} \\
C2 & {$[0.05995,27.6984,0]$} \\
\hline
\end{tabular}

\section{REFERENCES}

[1] X. D. Xue, K. W. E. Cheng, Z. Zhang, J. K. Lin, D. H. Wang, Y. J. Bao, M. K. Wong, and N. Cheung, "Study of art of automotive active suspensions," in International Conference on Power Electronics Systems and Applications (PESA), June 2011, pp. 1-7.

[2] D. Karnopp, "Theoretical limitations in active vehicle suspensions," Vehicle System Dynamics, vol. 15, no. 1, pp. 41-54, 1986.

[3] N. H. Amer, R. Ramli, W. N. L. Mahadi, and M. A. Z. Abidin, "A review on control strategies for passenger car intelligent suspension system," in International Conference on Electrical, Control and Computer Engineering (INECCE), June 2011, pp. 404-409.

[4] J. Cross, "Farewell to rock and roll." Automotive Engineer, vol. 24, no. 7 , p. $42,1999$.

[5] L. Teschler, S. J. Mraz, and S. L. Koucky, "CL500 Mercedes - No squat, no dive," Machine Design, vol. 72, no. 12, p. 160, 2000.

[6] Öhlins, "Öhlins launch semi-active upgrade for Multistrada S," 2013 [Online]. Available: http://www.ohlins.com/About-the-company/Newsnew/Ohlins-launch-semi-active-upgrade-for-Multistrada-S/

[7] R. Aucock, "Future shocks," Automotive Engineer, vol. 32, no. 6, pp. 27-28, 2007.

[8] S. A. Evangelou, D. Dini, O. De Meerschman, A. Tocatlian, C. Kneip, and C. Palas, "Variable-geometry suspension apparatus and vehicle comprising such apparatus," PCT application WO 2012/025705 A1, July, 2011.

[9] C. Arana, S. A. Evangelou, and D. Dini, "Pitch angle reduction for cars under acceleration and braking by active variable geometry suspension," in 51st IEEE Conference on Decision and Control (CDC), 2012, pp. 4390-4395.

[10] R. S. Sharp and S. A. Hassan, "An evaluation of passive automotive suspension systems with variable stiffness and damping parameters," Vehicle System Dynamics, vol. 15, no. 6, pp. 335-350, 1986.

[11] R. S. Sharp, "Variable geometry active suspension for cars," Computing Control Engineering Journal, vol. 9, no. 5, pp. 217-222, oct 1998.

[12] V. D. Knaap, "Design of a low power anti-roll/pitch system for a passenger car," Ph.D. dissertation, Vehicle Research Laboratory, Delft University of Technology, 1989.

[13] W.-J. Evers, A. Teerhuis, A. van der Knaap, I. Besselink, and H. Nijmeijer, "The electromechanical low-power active suspension: Modeling, control, and prototype testing," Journal of Dynamic Systems, Measurement, and Control, vol. 133, no. 4, p. 041008, 2011. 
[14] W.-J. Evers, I. Besselink, A. Teerhuis, and H. Nijmeijer, "On the achievable performance using variable geometry active secondary suspension systems in commercial vehicles," Vehicle System Dynamics, vol. 49, no. 10 , pp. $1553-1573,2011$.

[15] U. Lee and C. Han, "A suspension system with a variable roll centre for the improvement of vehicle handling characteristics," Proceedings of the Institution of Mechanical Engineers, Part D: Journal of Automobile Engineering, vol. 215, no. 6, pp. 677-696, 2001.

[16] B. Nemeth and P. Gaspar, "Integration of control design and variable geometry suspension construction for vehicle stability enhancement," in 50th IEEE Conference on Decision and Control and European Control Conference (CDC-ECC), 2011, pp. 7452-7457.

[17] A. Goodarzi, E. Oloomi, and E. Esmailzadeh, "Design and analysis of an intelligent controller for active geometry suspension systems," Vehicle System Dynamics, vol. 49, no. 1-2, pp. 333-359, 2011.

[18] S. A. Evangelou, "Control of motorcycles by variable geometry rear suspension," in IEEE International Conference on Control Applications (CCA), sept 2010, pp. 148-154.

[19] J. Dixon, Suspension geometry and computation. Wiley Online Library, 2009.

[20] M. Fallah, R. Bhat, and W. F. Xie, "Optimized control of semiactive suspension systems using $\mathrm{H}$-infinity robust control theory and current signal estimation," IEEE/ASME Trans. Mechatronics, vol. 17, no. 4, pp. 767-778, Aug. 2012.

[21] D. Maher and P. Young, "An insight into linear quarter car model accuracy," Vehicle System Dynamics, vol. 49, no. 3, pp. 463-480, 2011.

[22] Anon., AutoSim 2.5+ Reference Manual, Mechanical Simulation Corporation, 709 West Huron, Ann Arbor MI, 1998, http://www.carsim.com/.

[23] A. Alleyne and J. K. Hedrick, "Nonlinear adaptive control of active suspensions," IEEE Transactions on Control Systems Technology, vol. 3, no. 1, pp. 94-101, Mar. 1995.

[24] A. Kruczek, A. Stribrsky, J. Honcu, and M. Hlinovsky, "Controller choice for car active suspension," International Journal of Mechanics, vol. 3, pp. 61-68, 2009

[25] W. Sun, H. Gao, and O. Kaynak, "Adaptive backstepping control for active suspension systems with hard constraints," IEEE/ASME Trans. Mechatronics, vol. 18, no. 3, pp. 1072-1079, 2013.

[26] A. Hughes and B. Drury, Electric Motors and Drives: Fundamentals, Types and Applications. Elsevier Science, 2013.

[27] P. Pillay and R. Krishnan, "Modeling, simulation, and analysis of permanent-magnet motor drives, Part I: The permanent-magnet synchronous motor drive," IEEE Trans. Ind. Appl., vol. 25, no. 2, pp. 265273, Mar./Apr. 1989.

[28] R. Monajemy, "Control strategies and parameter compensation for permanent magnet synchronous motor drives," Ph.D. dissertation, Virginia Polytechnic Institute and State University, 2000.

[29] S. Morimoto, Y. Tong, Y. Takeda, and T. Hirasa, "Loss minimization control of permanent magnet synchronous motor drives," IEEE Transactions on Industrial Electronics, vol. 41, no. 5, pp. 511-517, 1994.

[30] N. Urasaki, T. Senjyu, and K. Uezato, "Investigation of influences of various losses on electromagnetic torque for surface-mounted permanent magnet synchronous motors," IEEE Transactions on Power Electronics, vol. 18, no. 1, pp. 131-139, Jan. 2003.

[31] R. Montague, C. Bingham, and K. Atallah, "Servo control of magnetic gears," IEEE/ASME Trans. Mechatronics, vol. 17, no. 2, pp. 269-278, 2012.

[32] K. Johan Åström and L. Rundqwist, "Integrator windup and how to avoid it," in American Control Conference, 1989, pp. 1693-1698.

[33] R. Krishnan, Permanent Magnet Synchronous and Brushless DC Motor Drives. CRC Press/Taylor \& Francis, 2010.

[34] C. Cavallaro, A. Di Tommaso, R. Miceli, A. Raciti, G. Galluzzo, and M. Trapanese, "Efficiency enhancement of permanent-magnet synchronous motor drives by online loss minimization approaches," IEEE Trans. Ind. Electron., vol. 52, no. 4, pp. 1153-1160, 2005.

[35] P. Krause, O. Wasynczuk, and S. Sudhoff, Analysis of Electric Machinery and Drive Systems. Wiley-IEEE Press, 2002.

[36] R. S. Sharp and D. J. N. Limebeer, "A motorcycle model for stability and control analysis," Multibody System Dynamics, vol. 6, no. 2, pp. 123-142, 2001.

[37] D. J. N. Limebeer, R. S. Sharp, and S. A. Evangelou, "The stability of motorcycles under acceleration and braking," Proceedings of the Institution of Mechanical Engineers, Part C: Journal of Mechanical Engineering Science, vol. 215, no. 9, pp. 1095-1109, 2001.

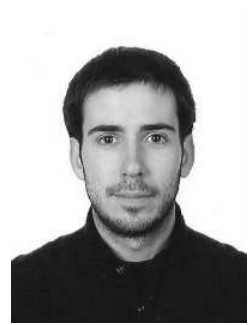

Carlos Arana is a IEEE Student Member since 2012. He received the B.A./M.Eng. degree in industrial engineering (2008) and the M.Sc. degree in applied and computational mechanical engineering (2009) from the Public University of Navarre (UPNa), Spain. He received the M.Sc. degree in advanced mechanical engineering (2011) from Imperial College London, United Kingdom, where he is currently working toward the Ph.D. degree. From 2008 to 2010, he worked as a Mechanical Engineer for Acciona Windpower, Navarre, Spain. His research interests are vehicle dynamics, and the modeling, simulation and control of mechatronic systems.

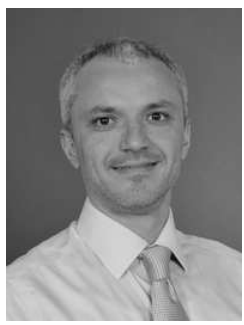

Simos A. Evangelou received the B.A./M.Eng. degree in electrical and information sciences from the University of Cambridge, United Kingdom, in 1999 and the Ph.D. degree in control engineering from Imperial College London, in 2004. In 2006 he was appointed a lecturer at Imperial College London, for the departments of mechanical and electrical and electronic engineering. Previously he worked as a research associate from 2004 to 2005 . He is a member of IFAC technical committee Automotive Control. He is a Fellow of the Higher Education Academy and a Member of the IEEE, the ASME and the IET. His research interests include the modelling, stability analysis and control of mechanical and mechatronic systems, and optimal driver behaviour and optimal tracking control in vehicle dynamics applications.

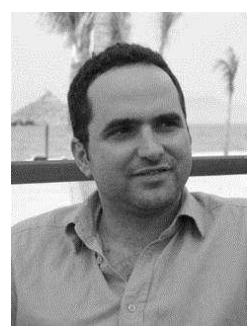

Daniele Dini received his M.Eng. in mechanical engineering at the Politecnico di Bari (Italy) in 2000 and a D.Phil. in engineering science in 2004 from the University of Oxford. He is a Reader in the department of mechanical engineering at Imperial College London, after joining the department in 2006. He is a chartered engineer, a member of the ASME, IMechE, and IET and a fellow of the Higher Education Academy. He is also a member of a number of editorial boards of international journals and chairman of the IMechE tribology group. His research interests include design against fatigue, fracture mechanics, structural integrity, tribology, mechanics of transmissions and bearings, material characterisation and advanced numerical modelling of complex interfaces. 